\title{
Obesity in African women in the North West Province, South Africa is associated with an increased risk of non-communicable diseases: the THUSA study
}

\author{
H. S. Kruger*, C. S. Venter and H. H. Vorster \\ School of Physiology, Nutrition and Family Ecology, Potchefstroom University for CHE, Potchefstroom 2531, South Africa
}

(Received 12 December 2000 - Revised 25 June 2001 - Accepted 16 August 2001)

\begin{abstract}
The objective of the present study was to assess the relationship between anthropometric measurements and risk factors for non-communicable diseases (NCD) in South African black women. A cross-sectional sample of 1040 apparently healthy black female volunteers, 15-70 years old, was recruited from thirty-seven randomly selected sites in the North West Province, stratified according to level of urbanisation. We analysed the association between BMI, waist:hip (WHR), waist circumference (WC) and skinfold measurements and the following risk factors for NCD: blood pressure, serum lipids, fasting serum glucose and insulin and plasma fibrinogen, by using age-adjusted correlation analyses and stepwise regression analysis. Of the subjects, $28.6 \%$ were obese (BMI $>30)$. After adjustment for age and smoking status, BMI correlated significantly with diastolic blood pressure $(r 0 \cdot 21, P=0 \cdot 037)$, serum triacylglycerols (TG) $(r 0 \cdot 30, P=0 \cdot 003)$, fasting glucose $(r 0.29, P=0.005)$ and $\log$ fasting insulin $(r 0.24, P=0.02)$. There was a significant negative correlation between BMI and HDL-cholesterol $(r-0.38, P<0.001)$. Similar but stronger correlations were found between both WC and WHR and these risk factors. Together with age, WC was a significant predictor of TG, HDL-cholesterol and fasting glucose in regression analysis, while subscapular skinfold was a significant predictor of diastolic blood pressure and fasting glucose concentration. Triceps skinfold was a significant predictor of total serum cholesterol, LDL-cholesterol, plasma fibrinogen and the insulin sensitivity index. Measures of obesity, particularly WC, are associated with the risk for NCD in black South African women, in which a high rate of obesity has been found.
\end{abstract}

Obesity: Black women: Non-communicable disease risk factors

There is controversy in the literature, and a lack of evidence regarding the detrimental effects of obesity on risk factors of non-communicable disease (NCD) in African women. 'Healthy obesity' was first described by Walker et al. (1989) in rural black women, when one or more of the adverse sequelae of obesity could be found in only $12.5 \%$ of the obese women studied and $87.5 \%$ were free of any sign of the metabolic syndrome. The difference between 'healthy obesity' and 'unhealthy obesity' could be that there are two different types, namely carbohydrate-induced and fatinduced obesity (Walker \& Segal, 1980). It has been speculated that even severe obesity in black women may be far less detrimental than in white women (Walker \& Segal, 1980; Walker et al. 1989). The authors stated therefore that 'obesity is not essentially noxious within the context of a low-fat, low-animal protein intake.' Excess visceral fat, rather than generalised or gynoid obesity, seems to be associated with an increased prevalence of risk factors for NCD (Lapidus et al. 1984; Larsson et al. 1992). More evidence for the harmful effects of abdominal obesity became available from the Nurses' Health Study, in which it was found that a higher waist:hip ratio (WHR) and a larger waist circumference (WC) were associated with an increased risk of $\mathrm{CHD}$, even after controlling for BMI (Rexrode et al. 1998). However, other researchers (Frayn, 1997; Seidell \& Bouchard, 1997) are of the opinion that both total and visceral fat are strong determinants of NCD.

In a study that included 574 rural and 468 urban black South African women, relatively high prevalences of moderate risk hypercholesterolaemia and mild hypertension were found (Mollentze et al. 1995). About one quarter $(27.5 \%)$ to more than half $(54 \%)$ of the subjects in the

\footnotetext{
Abbreviations: BP, blood pressure; NCD, non-communicable disease; PAI, physical activity index; SSF, subscapular skinfold thickness; TG, triacylglycerol; THUSA, Transition and Health during Urbanisation of South Africans; TSF, triceps skinfold; WHR, waist:hip ratio; WC, waist circumference.

* Corresponding author: Dr H. S. Kruger, fax +27 18299 2799, email vgehsk@ puknet.puk.ac.za
} 
different age groups were obese. The authors recommended that measures must be taken to prevent a future epidemic of atherosclerotic vascular disease in South Africa's black population and that the adverse effects of obesity in black women should be emphasised (Mollentze et al. 1995). Clearly, more information on possible adverse effects of obesity in African women is needed.

The aim of the present study was to examine the relationship between anthropometric measurements and risk factors for NCD among African women. Specific objectives included the assessment of the relationship between indices of obesity and blood pressure, serum lipids, fasting serum glucose and insulin concentrations and plasma fibrinogen. The present study formed part of the Transition and Health during Urbanisation of South Africans (THUSA) study, in which changes in health risk during urbanisation of Africans in the North West Province of South Africa are monitored.

\section{Methods}

Subjects

The subjects were recruited according to a stratified sampling frame from thirty-seven randomly selected sites in the province, based on data of population density. The sites were selected from the four quarters of the province in order to ensure inclusion of both rural and urban subjects. Five strata of urbanisation were defined, namely those living in rural areas in traditional villages (stratum 1), farm workers (stratum 2), those living in informal settlements close to towns (stratum 3), those living in established townships with access to water and electricity (stratum 4) and fully westernised individuals, living in upper-class urban areas (stratum 5). A total of 1040 black female subjects, aged 15-70 years, were included. Exclusion criteria were pregnancy, lactation, drunkenness, chronic diseases and chronic drug treatment. The protocol was described in detail by Vorster et al. (2000). Local organisers at each site helped with the recruitment of subjects and explained the study protocol to the subjects. Subjects were requested to fast overnight before the day of the study. Fasting status was confirmed when the subjects reported on the day of the study.

Trained interviewers, using a structured questionnaire, obtained demographic data, including educational status, total household income and smoking status (current smoker $v$. non-smoker) as categorical variables. A validated quantitative food frequency questionnaire and food picture books were used by the interviewers to collect dietary intake data (Venter et al. 2000). Total energy and nutrient intakes were calculated using a computer program based on South African food composition tables (Langenhoven et al. 1991). A questionnaire based on the questionnaire of Baecke et al. (1982) and standardised specifically for this population (Kruger et al. 2000) was used to obtain data on habitual physical activity. Physical activity was calculated according to a modification of the Baecke equation (Baecke et al. 1982) and expressed as a continuous variable, the physical activity index (PAI) (Kruger et al. 2000). Blood pressure (BP) was measured according to World Health Organization (1978) guidelines after a 5 min rest in the sitting position.
Two readings at 2-min intervals were obtained using a tablemodel sphygmomanometer (Model ALPK2; Tycos ${ }^{\circledR}$, Arden, NC, USA) and the second reading was recorded. An appropriately large cuff was used for obese subjects. The diastolic pressure was taken as the point of disappearance of the Korotkoff phase $\mathrm{V}$ sounds. The following anthropometric variables were measured by trained biokineticists using standard methods (Norton \& Olds, 1996): height, weight, WC, hip circumference, triceps skinfold (TSF) and subscapular skinfold thickness (SSF). WC was taken at the narrowest point between the lower rib border and the iliac crest. If there was no obvious narrowing, the measurement was taken at the midpoint between these two positions. Hip circumference was measured at the point of maximal circumference over the buttocks when viewed from the side. Both measurements were taken at the end of normal expiration and were recorded to the nearest $0.5 \mathrm{~cm}$. BMI and WHR were calculated as the weight $(\mathrm{kg})$ divided by the square of the height $(\mathrm{m})$, and the WC divided by the hip circumference, respectively.

Blood samples were drawn from the vena cephalica using a sterile butterfly infusion set and syringes (21 gauge). Serum was prepared by centrifugation at $3000 \mathrm{rpm}$ for $15 \mathrm{~min}$. Serum samples were frozen in $1 \mathrm{ml}$ portions at $-20^{\circ} \mathrm{C}$ for 1 to $4 \mathrm{~d}$ while in the research area and then at $-84^{\circ} \mathrm{C}$ in the laboratory. Citrated blood samples $(0.5 \mathrm{ml}$ $0.1 \mathrm{~mol}$ citrate/1, $\mathrm{pH} 4.5-4.8$, plus $4.5 \mathrm{ml}$ venous blood) were centrifuged at $3000 \mathrm{rpm}$ for $10 \mathrm{~min}$. The citrated plasma was divided into five portions, frozen at $-20^{\circ} \mathrm{C}$ for 1 to $4 \mathrm{~d}$ in the field laboratory and then at $-84^{\circ} \mathrm{C}$ in the laboratory. The following biochemical assay methods were used to analyse plasma and serum samples: for fibrinogen the Clauss method (Instrumentation Laboratories, Milan, Italy), for total serum cholesterol, triacylglycerols (TG) and glucose the DAX profile (Technicon DAX 48, Tarry Town, NY, USA), for HDL-cholesterol the Merck hand method (Merck reagent kit 14350; Merck Diagnostics, Darmstadt, Germany), LDL-cholesterol was calculated (Friedewald equation; Friedewald et al. 1972) and serum insulin was measured using a radioimmunoassay kit (Immuno Biological Laboratories, Hamburg, Germany).

The serum lipid analyses were done in the laboratory of the Department of Chemical Pathology of the University of Pretoria with appropriate quality control methods. Plasma fibrinogen concentrations were measured in the laboratory of the Nutrition Research Group, Potchefstroom University, using the ACL 200 (Milan, Italy) and an internationally recognised fibrinogen control plasma (Code 89/644, NIBSC, Herts.) as external standard.

\section{Statistical analyses}

Statistical analyses were performed using SPSS software (SPSS, 1995). Due to skewed distributions fasting serum insulin, TG and plasma fibrinogen concentrations were logarithmically transformed and non-parametric methods were used for correlation analyses. Partial Spearman's correlation analyses were performed to assess the relationship between anthropometric variables (BMI, WC and WHR) and risk factors for NCD, adjusted for age and smoking status, since age and smoking were significantly 
associated with BMI in univariate analysis of variance (data not shown). The mean values for most of the risk factors increased with age, which also made the adjustment for age necessary. Spearman's correlation coefficients were also calculated for the correlation among the anthropometric measurements (BMI and WC or WHR). A $P$ value of $<0.05$ (two-tailed) was considered to be significant.

Stepwise linear regression analysis was used to assess the variance in NCD risk factors explained independently by each of the anthropometric indices of obesity and fat distribution (BMI, TSF, SSF, WC and WHR). Since the skinfold thicknesses of some grossly obese subjects (TSF and SSF $>50 \mathrm{~mm}$ ) could not be measured accurately by caliper (Norton \& Olds, 1996), the association between these measures and risk factors for NCD were assessed in a stepwise regression, excluding the most obese subjects ( $n$ $224,21.5 \%$ and $n 195,18.8 \%$ respectively) from the analyses. The exclusion of these subjects did not imply, however, that only non-obese subjects were studied, since $28.6 \%$ of the subjects were obese and $25.2 \%$ were overweight. Only grossly obese subjects were excluded in the analyses of the association between TSF and SSF, respectively and risk factors. It is thus possible that the association between SSF and TSF and the risk factors measured may be underestimated. In each analysis, the anthropometric indices were used as independent variables and one of the NCD risk factors as the dependent variable.

An insulin sensitivity index was calculated as 10000 times the reciprocal of the product of fasting insulin concentration and fasting glucose concentration (Donahue et al. 1988).

\section{Ethical considerations}

The subjects gave informed consent and the study was approved by the Ethics Committee of the Potchefstroom University.

\section{Results}

\section{Anthropometry}

The anthropometric and metabolic variables of the study population are shown in Table 1. A mean BMI of 26.90 (SD $6.81) \mathrm{kg} / \mathrm{m}^{2}$ was found, $25.2 \%$ of the subjects were overweight with BMI $>25$ and $<30$ ) and $28.6 \%$ were obese (BMI >30). Increases in BMI, skinfold thicknesses, WHR and WC were found with age (Table 1), with a considerable increase between the age groups $15-24$ to 25-34 years.

According to the USDA document of Expert Panel on the Identification, Evaluation and Treatment of Overweight in Adults (1998), to identify persons with a high risk of death from NCD a cut-off point for WHR has been specified at 0.80 for women, indicating central or abdominal obesity. From the age group 35-44 years and older more than $33 \%$ of women had higher WHR than this cut-off point (Table 2). A WC exceeding $80 \mathrm{~cm}$ for women has similarly been identified as a cut-off point for central obesity (Lean et al. 1995). Table 2 also shows the rate of central obesity according to this WC cut-off point, which is higher than when WHR is used as a measure of central obesity. There was a strong statistically significant correlation between BMI and WC $(r$ 0.897, $P<0.001)$ and a weaker, but significant, correlation between BMI and WHR $(r 0 \cdot 370$, $P<0 \cdot 001$ ), after adjustment for age and smoking status, in the total study sample.

\section{Blood pressure}

There was an increase in both the mean systolic and diastolic BP with age (Table 1). After adjustment for age and smoking, Spearman's partial correlation coefficients showed that BMI correlated positively with diastolic BP ( $r 0 \cdot 212, P=0 \cdot 037)$. The correlation between WC and WHR, respectively, and both systolic (WC, $r$ 0.209, $P=0.04$,

Table 1. Anthropometric and metabolic variables of the subjects $(n 1003)^{*}$ (Mean and standard deviation, or geometric mean and $95 \% \mathrm{Cl}$ )

\begin{tabular}{|c|c|c|c|c|c|c|c|c|c|c|}
\hline \multirow[t]{2}{*}{ Age group (years)... } & \multicolumn{2}{|c|}{$15-24$} & \multicolumn{2}{|c|}{$25-34$} & \multicolumn{2}{|c|}{$35-44$} & \multicolumn{2}{|c|}{$45-54$} & \multicolumn{2}{|c|}{$55-70$} \\
\hline & Mean & SD & Mean & SD & Mean & SD & Mean & SD & Mean & SD \\
\hline$n$ & \multicolumn{2}{|c|}{185} & \multicolumn{2}{|c|}{279} & \multicolumn{2}{|c|}{233} & \multicolumn{2}{|c|}{177} & \multicolumn{2}{|c|}{129} \\
\hline Plasma fibrinogen $(\mathrm{g} / \mathrm{l}) \dagger$ & \multirow{2}{*}{\multicolumn{2}{|c|}{$\begin{array}{l}3.32 \\
3 \cdot 21,3 \cdot 71\end{array}$}} & \multirow{2}{*}{\multicolumn{2}{|c|}{$\begin{array}{l}3.39 \\
3.26,3.60\end{array}$}} & \multirow{2}{*}{\multicolumn{2}{|c|}{$\begin{array}{l}3.53 \\
3 \cdot 34,3 \cdot 71\end{array}$}} & \multirow{2}{*}{\multicolumn{2}{|c|}{$\begin{array}{l}3.49 \\
3.42,3.85\end{array}$}} & \multirow{2}{*}{\multicolumn{2}{|c|}{$\begin{array}{l}3.68 \\
3.51,4.09\end{array}$}} \\
\hline $95 \% \mathrm{Cl}$ & & & & & & & & & & \\
\hline Total cholesterol (mmol/l) & $3 \cdot 72$ & 0.85 & 3.93 & 0.86 & $4 \cdot 35$ & 1.05 & 4.57 & $1 \cdot 11$ & 5.09 & $1 \cdot 21$ \\
\hline HDL-cholesterol (mmol/l) & $1 \cdot 06 \ddagger$ & 0.27 & $1 \cdot 13$ & 0.29 & $1 \cdot 17$ & 0.31 & $1 \cdot 20$ & 0.34 & $1 \cdot 27$ & 0.42 \\
\hline HDL:total cholesterol ratio & \multicolumn{2}{|c|}{0.28} & \multicolumn{2}{|c|}{0.29} & \multicolumn{2}{|c|}{0.27} & \multicolumn{2}{|c|}{0.26} & \multicolumn{2}{|c|}{0.25} \\
\hline LDL-cholesterol (mmol/l) & $2 \cdot 20 \ddagger$ & 0.77 & $2 \cdot 38$ & 0.80 & $2 \cdot 76$ & 1.02 & $2 \cdot 98$ & $1 \cdot 14$ & 3.42 & $1 \cdot 12$ \\
\hline Serum triacylglycerols $(\mathrm{mmol} / \mathrm{l}) \dagger$ & \multirow{2}{*}{\multicolumn{2}{|c|}{$\begin{array}{l}0.78 \S \\
0.76,0.88\end{array}$}} & \multirow{2}{*}{\multicolumn{2}{|c|}{$\begin{array}{l}0.89 \\
0.88,1.04\end{array}$}} & \multirow{2}{*}{\multicolumn{2}{|c|}{$\begin{array}{l}1 \cdot 12 \\
1 \cdot 10,1 \cdot 28\end{array}$}} & \multirow{2}{*}{\multicolumn{2}{|c|}{$\begin{array}{l}1 \cdot 26 \\
1 \cdot 19,1.49\end{array}$}} & \multirow{2}{*}{\multicolumn{2}{|c|}{$\begin{array}{l}1.44 \\
1.40,2 \cdot 11\end{array}$}} \\
\hline $95 \% \mathrm{Cl}$ & & & & & & & & & & \\
\hline Fasting serum insulin $(\mu \mathrm{U} / \mathrm{ml}) \dagger$ & \multirow{2}{*}{\multicolumn{2}{|c|}{$\begin{array}{l}25 \cdot 9 \\
24 \cdot 8,30 \cdot 8\end{array}$}} & \multirow{2}{*}{\multicolumn{2}{|c|}{$\begin{array}{l}23 \cdot 5 \\
23 \cdot 1,30 \cdot 9\end{array}$}} & \multirow{2}{*}{\multicolumn{2}{|c|}{$\begin{array}{l}22 \cdot 7 \\
\quad 22 \cdot 4,32 \cdot 2\end{array}$}} & \multirow{2}{*}{\multicolumn{2}{|c|}{$\begin{array}{l}17 \cdot 89 \\
17 \cdot 3,22 \cdot 6\end{array}$}} & \multirow{2}{*}{\multicolumn{2}{|c|}{$\begin{array}{l}21 \cdot 9 \\
19 \cdot 9,33 \cdot 0\end{array}$}} \\
\hline $95 \% \mathrm{Cl}$ & & & & & & & & & & \\
\hline Serum glucose (mmol/l) & 4.45 & 0.67 & 4.66 & 1.98 & 4.95 & $2 \cdot 21$ & 4.90 & 1.58 & $5 \cdot 41$ & $2 \cdot 80$ \\
\hline Systolic blood pressure (mmHg) & $116 \cdot 3 \ddagger$ & $12 \cdot 8$ & $118 \cdot 4$ & $15 \cdot 2$ & $128 \cdot 8$ & $19 \cdot 3$ & $137 \cdot 8$ & $24 \cdot 5$ & $143 \cdot 2$ & $22 \cdot 7$ \\
\hline Diastolic blood pressure $(\mathrm{mmHg})$ & $71.9 \ddagger$ & $9 \cdot 1$ & $73 \cdot 3$ & $10 \cdot 8$ & $81 \cdot 1$ & $13 \cdot 7$ & $85 \cdot 7$ & 14.9 & $85 \cdot 7$ & 11.9 \\
\hline Waist circumference (cm) & $68 \cdot 12 \ddagger$ & $8 \cdot 12$ & $77 \cdot 00$ & $12 \cdot 1$ & 82.90 & $12 \cdot 6$ & $81 \cdot 80$ & $13 \cdot 6$ & $81 \cdot 81$ & $14 \cdot 1$ \\
\hline Waist:hip ratio & $0.71 \ddagger$ & 0.05 & 0.75 & 0.06 & 0.78 & 0.07 & 0.80 & 0.06 & 0.80 & 0.08 \\
\hline BMI $\left(\mathrm{kg} / \mathrm{m}^{2}\right)$ & $23 \cdot 2 \ddagger$ & $4 \cdot 76$ & $26 \cdot 7$ & $6 \cdot 58$ & 28.9 & $6 \cdot 67$ & $27 \cdot 9$ & $7 \cdot 69$ & $28 \cdot 0$ & $6 \cdot 90$ \\
\hline
\end{tabular}

* For details of subjects and procedures, see p. 734. The number of subjects for which the variables were measured varied due to missing values. † Geometric mean and $95 \% \mathrm{Cl}$ were calculated since data were not normally distributed.

$\ddagger$ Mean values of the youngest age group were significantly different from those of age groups $35-44$ and higher $(P=0.001)$.

$\S$ Geometric mean value of the youngest age group was significantly different from those of age groups $45-54$ and $55-70$ years $(P=0 \cdot 003)$. 
Table 2. Women within each age decile with waist:hip ratio (WHR) and waist circumference (WC) exceeding the cut-off points $(0.80$ and $80 \mathrm{~cm}$ respectively), according to NHANES I 85 th percentiles, indicating central obesity*

\begin{tabular}{|c|c|c|c|c|c|c|c|c|c|c|c|c|}
\hline \multirow[t]{2}{*}{ Age group (years)... } & \multicolumn{2}{|c|}{$15-70$ (total) } & \multicolumn{2}{|c|}{$15-24$} & \multicolumn{2}{|c|}{$25-34$} & \multicolumn{2}{|c|}{$35-44$} & \multicolumn{2}{|c|}{$45-54$} & \multicolumn{2}{|c|}{$55-70$} \\
\hline & $n$ & $\%$ & $n$ & $\%$ & $n$ & $\%$ & $n$ & $\%$ & $n$ & $\%$ & $n$ & $\%$ \\
\hline Total $n$ & 1038 & & 185 & & 295 & & 234 & & 179 & & 145 & \\
\hline WHR & 294 & $28 \cdot 3$ & 13 & $7 \cdot 0$ & 46 & $15 \cdot 6$ & 90 & 38.5 & 81 & $45 \cdot 2$ & 64 & 44.1 \\
\hline WC & 406 & 39.1 & 22 & 11.9 & 94 & 31.9 & 127 & 54.3 & 89 & $49 \cdot 7$ & 74 & 51.0 \\
\hline
\end{tabular}

${ }^{*}$ For details of subjects and procedures, see Table 1 and p. 734.

WHR, $r$ 0.276, $P=0 \cdot 006$ ) and diastolic BP (WC, $r$ 0.279, $P=0.006$, WHR, $r 0.292, P=0.004)$ were also statistically significant (Fig. 1).

Using stepwise linear regression analysis with BMI, WC, TSF and SSF as independent variables, together with age, smoking, level of urbanisation and PAI, most of the variance in diastolic BP was explained by SSF thickness. Level of urbanisation, age and SSF together explained $24.5 \%$ of the variance in diastolic BP. The most significant predictors of systolic BP were age, level of urbanisation and smoking status.

\section{Serum lipids}

The serum total cholesterol, LDL-cholesterol, HDLcholesterol and TG concentrations increased with age (Table 1). The HDL:total cholesterol ratio of the subjects in all age groups was higher than the proposed beneficial ratio of 0.20 (Rossouw et al. 1988), but decreased slightly with age from $0 \cdot 28-0 \cdot 25$. Serum TG concentration is generally positively correlated with visceral fat accumulation and may be a confounding factor in the association between WC and WHR and other serum lipids (James et al. 1997). For this reason correlation analyses were also done with an adjustment for TG concentration.

When adjustments for age and smoking status were made, BMI, WHR and WC, respectively, correlated positively with TG (BMI, $r 0 \cdot 302, P=0.003$; WC, $r 0.436, P<0 \cdot 001$; WHR, $r 0.554, P<0.001)$ and negatively with HDLcholesterol (BMI, $r-0.375, P<0.001$; WC, $r-0.397$, $P<0.001$; WHR, $r-0.307, P=0.002)$. The relationships between anthropometric variables and NCD risk factors are shown in Fig. 1. After further adjustment for TG, similar correlations as before adjustment between BMI and HDL-cholesterol $(r-0 \cdot 211, P<0 \cdot 001)$ were found. WC $(r-0.262, \quad P<0 \cdot 001)$, as well as WHR $(r-0.143$, $P<0.001)$ also correlated negatively with HDL-cholesterol after adjustment for serum TG concentration.

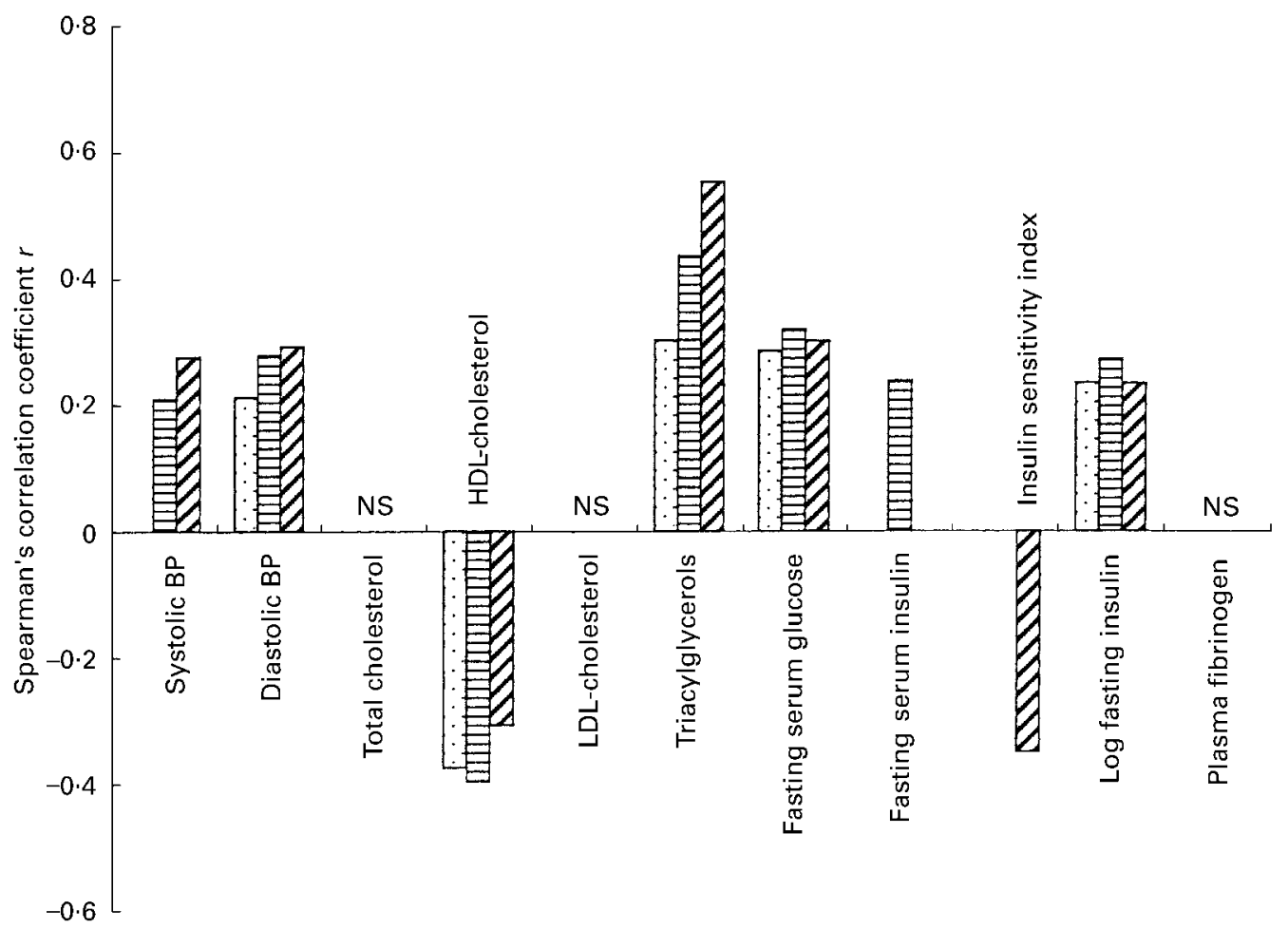

Fig. 1. Spearman's partial correlation coefficient $(r)$ for the correlation between anthropometric variables and risk factors for non-communicable diseases (adjusted for age and smoking status). All correlations are significant at $P<0.05$ unless indicated as NS. 关, BMI; 目, waist circumference; waist:hip. BP, blood pressure. 
Using stepwise regression analysis with the indices of obesity as independent variables and the NCD risk factors, including PAI, total energy, alcohol and fat intake as dependent variables, most of the variance in total serum cholesterol and LDL-cholesterol were explained by age, TSF and serum TG concentration. PAI $(P=0 \cdot 25)$, total energy intake $(P=0 \cdot 152)$ and total fat intake $(P=0.949)$ were not significant predictors of total cholesterol and also not of LDL-cholesterol or TG. The most significant predictors of HDL-cholesterol in the stepwise regression model were age, WC and smoking status, explaining $19 \%$ of the variance in HDL-cholesterol. PAI $(P=0 \cdot 702)$ and dietary intakes (total energy, $P=0 \cdot 818$; total fat, $P=0 \cdot 139$; alcohol, $P=0 \cdot 242$ ) were not significant predictors of HDLcholesterol in this regression model (Table 3).

\section{Fasting serum glucose and insulin}

Subjects in the oldest age group had a higher mean fasting serum glucose concentration compared with subjects in the younger groups (Table 1). In contrast to this pattern of differences in serum glucose, the geometric mean of the fasting serum insulin was the lowest in the age group 45-54 years, compared with the youngest and the oldest age groups (Table 2).

After adjustment for age and smoking status, BMI ( $r$ 0.286, $P=0.005$ ), WHR ( $r 0.301, P=0.003)$ and WC ( $r 0 \cdot 320, P=0 \cdot 001)$ correlated positively with fasting serum glucose (Fig. 1). In the regression model with serum glucose as the dependent variable, WC, BMI and SSF were significant predictors of fasting serum glucose and together explained $10.9 \%$ of the variance in serum glucose. Logarithmically transformed fasting serum insulin correlated positively with BMI ( $r 0.235, P=0.021)$, WC $(r 0.272$, $P=0.007)$ and WHR $(r$ 0.234, $P=0.021)$. The insulin sensitivity index, which indicates a favourable insulin sensitivity at higher values, correlated negatively with WHR ( $r-0 \cdot 35, P=0 \cdot 039$; Fig. 1$)$. With stepwise regression, age and level of urbanisation were significant predictors of fasting insulin (log transformed), which explained $23.9 \%$ of the variance in fasting serum insulin. Age and level of urbanisation, together with TSF, explained $22.1 \%$ of the variation in insulin sensitivity.

\section{Plasma fibrinogen}

Mean plasma fibrinogen concentration increased with age, but the geometric means of the plasma fibrinogen levels of the different age groups were not significantly different. In stepwise regression TSF and PAI were the only significant predictors of plasma fibrinogen.

The correlation between the anthropometric variables and risk factors for NCD are summarised in Fig. 1. In general, stronger correlations were found between WC and the risk factors, than between BMI and these risk factors. There was also a tendency for a stronger correlation between WC and risk factors than between WHR and the same variables. In Table 3 the statistically significant associations found with stepwise regression between anthropometric variables and risk factors for NCD are shown. Although the skinfold thicknesses of the grossly obese subjects (skinfold thickness $>50 \mathrm{~mm}$ ) could not be measured, statistically significant associations between both SSF and TSF and some of the risk factors for NCD were found.

\section{Discussion}

Results of cross-sectional studies should be interpreted with care, since associations between variables do not necessarily imply causality. The association of indices of obesity with risk factors for NCD in the subjects confirms the results of other studies in black populations in the USA (Folsom et al. 1991). The long incubation period of 30-40 years for CHD may be a reason for the present low prevalence of CHD in black South Africans, but may point to a possible imminent cardiovascular disease epidemic in the black population in South Africa (Mollentze et al. 1995). The salient results of the present study of the relationships between measures of obesity and risk factors for NCD will be discussed against this background.

Table 3. The variance in risk factors for non-communicable diseases (dependent variables) explained by anthropometric variables (independent variables) using stepwise regression analysis*

\begin{tabular}{|c|c|c|c|c|}
\hline Dependent variable & Significantly associated independent variable & $R^{2}$ & $\beta \dagger$ & $P$ \\
\hline Systolic blood pressure & - & - & - & - \\
\hline Diastolic blood pressure & SSF $\ddagger$ & 0.245 & $0 \cdot 151$ & 0.002 \\
\hline Total serum cholesterol & TSF§ & 0.235 & $0 \cdot 138$ & 0.004 \\
\hline Serum LDL-cholesterol & TSF§ & 0.297 & 0.121 & 0.041 \\
\hline Serum HDL-cholesterol & WC & $0 \cdot 190$ & -0.261 & $<0.001$ \\
\hline Serum triacylglycerols & WC & 0.247 & 0.153 & 0.005 \\
\hline \multirow[t]{3}{*}{ Fasting serum glucose } & WCף & 0.041 & 0.250 & $<0.001$ \\
\hline & BMI, & 0.070 & 0.296 & 0.026 \\
\hline & SSF & $0 \cdot 109$ & 0.355 & 0.010 \\
\hline Insulin sensitivity index & TSF§ & 0.221 & -0.192 & 0.026 \\
\hline Fasting serum insulin & - & - & - & - \\
\hline Plasma fibrinogen & TSF§ & 0.023 & 0.143 & 0.037 \\
\hline
\end{tabular}

SSF, subscapular skinfold thickness; TSF, triceps skinfold thickness; WC, waist circumference.

${ }^{*}$ For details of subjects and procedures, see Table 1 and p. 734.

† Standardised $\beta$-coefficient.

¥ Skinfold thicknesses were missing for grossly obese subjects (where SSF> $50 \mathrm{~mm} ; n 195,18.8 \%$ ).

§ Skinfold thicknesses were missing for grossly obese subjects (where TSF>50 mm; $n 224 ; 21.5 \%$ )

I The first independent variable which enters the regression analysis. 
The high rates of overweight $(25.2 \%)$ and obesity $(28.6 \%)$ in this sample are consistent with the results of Mollentze et al. (1995) in a South African black population. The relatively high percentage of women that exceeded the standard cut-off point of 0.80 for WHR (Expert Panel on the Identification, Evaluation, and Treatment of Overweight in Adults, 1998), and of $80 \mathrm{~cm}$ for WC (Lean et al. 1995), indicating central or abdominal obesity is in agreement with the results of Croft et al. (1995) and Folsom et al. (1991) for African-American subjects. Several authors are of the opinion that the WHR cut-off point of 0.80 may not be appropriate for all age and ethnic groups, since this cut-off point is based on cross-sectional data from Caucasian populations (Folsom et al. 1991; Ko et al. 1997). No cut-off points have been formulated for Africans.

The strong correlation between BMI and WC ( $r$ 0.897, $P<0 \cdot 001)$ is close to the correlation found by Grol et al. (1997) for a developing community. Conway et al. (1995) recommended that WC may be used as a simple yet sensitive measure of central fat distribution and a better predictor of abdominal obesity than WHR, specifically in African-American women. According to the results of the present study (Fig. 1) WC seems to be a better predictor of NCD risk factor prevalence than WHR. WC should preferably be measured as a measure of abdominal obesity in studies of risk factor prevalence in South African black populations.

Apparently visceral adiposity rather than total excessive body fat is associated with impaired glucose tolerance and hyperlipidaemia (Fujioka et al. 1987). Abdominal obesity was identified as an independent risk factor for CHD in both men and women (Lapidus et al. 1984) and in both black and white subjects (Folsom et al. 1991). It has been proposed that intra-abdominal fat, as reflected by a high WC, is highly lipolytic, causing an increased flux of fatty acids to the liver. With increased hepatic TG formation, there is a decreased hepatic clearance of insulin. The results of these metabolic changes would be increased concentrations of blood lipoproteins, glucose and insulin (Marin \& Bjorntorp, 1993).

An increase of BP with age in urban communities is a well-known phenomenon (Seedat et al. 1982). Obesity was similarly positively associated with systolic BP in both black and white subjects in the CARDIA and ARIC studies in the USA (Folsom et al. 1991), while the positive correlation between $\mathrm{BMI}$ and diastolic $\mathrm{BP}$ is consistent with the results of the NHANES II (Van Itallie, 1985). The positive correlation of both WC and WHR with BP are in line with the findings of other authors (Cox et al. 1997; Guagnano et al. 1997), who reported that indices of abdominal obesity (upper body obesity) were more strongly associated with BP than BMI.

Impaired glucose tolerance and insulin resistance associated with abdominal obesity lead to hyperinsulinaemia, which favours renal $\mathrm{Na}$ reabsorption and increased sympathetic activity and consequently hypertension (Modan et al. 1985; Landsberg, 1986). A significant negative correlation between insulin sensitivity index and both diastolic $(r-0.442, P=0.008)$ and systolic BP ( $r-0 \cdot 390, P=0 \cdot 021)$ was found. Higher levels of insulin sensitivity indicate a favourable index of glucose tolerance
(Donahue et al. 1988) and were in the present study associated with lower BP.

One of the reasons for the low incidence of CHD in black South Africans (Walker et al. 1991) may be the high prevalence of a favourable HDL-cholesterol:TC ratio, exceeding 0.20 (Steyn et al. 1991), also found in the present study (Table 1). Similar ratios have been reported for the African population of the Cape Peninsula (Steyn et al. 1991) and for black populations in the Free State of South Africa (Mollentze et al. 1995) and also a similar tendency of the ratio to decrease with age (Steyn et al. 1991; Mollentze et al. 1995). Although most subjects had favourably high HDL-cholesterol levels, HDL-cholesterol corrrelated negatively with BMI, WHR and WC, which indicates lower levels of protective HDL-cholesterol among the most obese subjects. The fact that PAI was not associated with HDLcholesterol in stepwise regression analysis may be due to the generally low physical activity of the total sample (Kruger et al. 2000). It is surprising that such high HDL-cholesterol concentrations were found in the subjects, of whom such a considerable percentage $(28.6 \%)$ were obese and many of the subjects $(67.2 \%)$ were physically relatively inactive (Kruger et al. 2000).

The total cholesterol and LDL-cholesterol concentrations of the subjects in the present study were similar to those of black subjects in the Cape Peninsula (Steyn et al. 1991). Total cholesterol and LDL-cholesterol were, however, significantly associated with TSF, which is an index of obesity (Table 3 ) and indicates a higher risk of CHD in the more obese subjects.

The significant positive correlations between both fasting glucose and log fasting serum insulin and BMI (Fig. 1) are consistent with the results of the CARDIA and ARIC studies (Folsom et al. 1991). The negative correlation between WHR and the insulin sensitivity index (Fig. 1) is an indication of decreased glucose tolerance in the more obese subjects with abdominal obesity.

Ernst (1991) proposed that a plasma fibrinogen level of higher than $3.5 \mathrm{~g} / \mathrm{l}$ is an independent risk factor for stroke and coronary artery disease. The geometric means of the plasma fibrinogen of the age groups 35-44 and 55-70 years were higher than $3.5 \mathrm{~g} / \mathrm{l}$ (Table 1 ). In the study reported here, no association between BMI and plasma fibrinogen was found. De Pergola et al. (1997) suggested that other factors may be more important than BMI per se in increasing fibrinogen levels in obese women. TSF, an index of upper-body obesity, was a significant predictor of plasma fibrinogen $(P=0 \cdot 037)$ in the present study. Physical activity was inversely related to plasma fibrinogen and also was a significant predictor of plasma fibrinogen $(P=0 \cdot 043)$. Increased physical activity has been associated with a reduction in plasma fibrinogen (Marckmann, 1995) and could be a link between obesity and increased plasma fibrinogen.

\section{Conclusion and recommendations}

High rates of obesity were found in these African women, with an increase in BMI, skinfold thicknesses, WC and WHR with increasing age. Obesity, especially abdominal obesity was associated with higher BP, lower HDLcholesterol levels, and higher TG, fasting serum glucose 
and insulin (Fig. 1). The differences in fasting insulin in the different age groups and the relationship between BMI and fasting insulin should be investigated in more detail. The results confirm the importance of abdominal obesity as a cardiovascular risk factor in African women (Lapidus et al. 1984; Larsson et al. 1992). In the present study WC showed a stronger correlation with most risk factors than WHR. This is in agreement with the results of Pouliot et al. (1994). However, BMI, reflecting general obesity, also provided useful information on cardiovascular risk (Table 3).

Although the mean HDL-cholesterol of the subjects in all age groups was high, indicating a protective effect against CHD, the HDL-cholesterol concentrations correlated negatively with both BMI and WC. Consequently, the protective effect of HDL-cholesterol decreased in the most obese subjects. It can therefore be concluded that obesity in African women is, as in other populations, associated with an increased risk of NCD.

The results of the present study do not confirm the concept of 'healthy obesity', but indicate that efforts should be made for the early diagnosis and effective treatment of obesity, combatting smoking in young black women and propagating the importance of a healthy lifestyle. Acceptable and effective intervention programmes should be developed to treat obesity in black women and especially to prevent excessive weight gain in young black women. A better understanding of the medical hazards of obesity should enhance motivation to prevent excessive weight gain.

\section{Acknowledgements}

The authors gratefully acknowledge the assistance of all members of the THUSA research team, especially Dr Annamarie Kruger, for drawing blood samples and statistical analyses, Professor Hans de Ridder and Dr Conrad Greer for supervising the anthropometry and Dr Una MacIntyre for supervising the dietary intake assessment. We thank the subjects for their cooperation. Financial support was granted by the South African Sugar Association, the National Research Foundation of South Africa and the Potchefstroom University for CHE.

\section{References}

Baecke JAH, Burema J \& Frijters JER (1982) A short questionnaire for the measurement of habitual physical activity in epidemiological studies. American Journal of Clinical Nutrition 36, 936-942.

Conway JM, Yanovski SZ, Avila NA \& Hubbard VS (1995) Visceral adipose tissue differences in black and white women. American Journal of Clinical Nutrition 61, 765-771.

Cox BD, Whichelow MJ, Ashwell M, Prevost AT \& Lejeune SRE (1997) Association of anthropometric indices with elevated blood pressure in British adults. International Journal of Obesity 21, 674-680.

Croft JB, Keenan NL, Sheridan DP, Wheeler FC \& Speers MA (1995) Waist to hip ratio in a biracial population: measurement implications and cautions for using guidelines to define high risk for cardiovascular disease. Journal of the American Dietetic Association 95, 60-64.

De Pergola GD, De Mitro VD, Giorgino F, Sciaraffia M, Minenna
A, Di Bari L, Pannaciuli N \& Giorgino R (1997) Increase in both pro-thrombotic and anti-thrombotic factors in obese premenopausal women: relationship with body fat distribution. International Journal of Obesity 21, 527-535.

Donahue RP, Orchard TJ, Becker DJ, Kuller LH \& Drash AL (1988) Physical activity, insulin sensitivity and the lipoprotein profile of young adults: the Beaver County Study. American Journal of Epidemiology 127, 95-103.

Ernst E (1991) Fibrinogen: an independent risk factor for cardiovascular disease. British Medical Journal 303, 596-597.

Expert Panel on the Identification, Evaluation, and Treatment of Overweight in Adults (1998) Clinical guidelines in the identification, evaluation, and treatment of overweight and obesity in adults: executive summary. American Journal of Clinical Nutrition 68, 899-917.

Folsom AR, Burke GL, Byers CL, Hutchinson RG, Heiss G, Flack JM, Jacobs DR \& Caan B (1991) Implications of obesity for cardiovascular disease in blacks: the CARDIA and ARIC studies. American Journal of Clinical Nutrition 53, 1604S$1611 \mathrm{~S}$.

Frayn K (1997) Visceral fat in relation to health: is it a major culprit or simply an innocent bystander? International Journal of Obesity 21, 1191-1192.

Friedewald WT, Levy RI \& Fredrickson DS (1972) Estimation of the concentration of LDL in plasma without use of the preparative ultracentrifuge method Clinical Chemistry 18, 499502.

Fujioka A, Matzuwaza V, Takunga K \& Tarui S (1987) Contribution of intra-abdominal fat accumulation to the impairment of glucose and lipid metabolism in human obesity. Metabolism 36, 54-59.

Grol MEC, Eimers JM, Alberts JF, Bouter LM, Gerstenbluth I, Halabi Y, Van Sonderen E \& Van den Heuvel WJA (1997) Alarmingly high prevalence of obesity in Curacao: data from an interview survey stratified for socio-economic status. International Journal of Obesity 21, 1002-1009.

Guagnano MT, Ballone E, Merlitti D, Murri R, Pace-Palitti V, Pilotti R \& Sensi S (1997) Association between anthropometric and ultrasound measurements of fatness with ambulatory blood pressure monitoring in obese women. International Journal of Obesity 21, 632-636.

James RW, Brulhart-Meynet MC, Lehman T \& Golay A (1997) Lipoprotein distribution and composition in obesity: their association with central adiposity. International Journal of Obesity 21, 1115-1120.

Ko GTC, Chan JCN, Woo J, Lau E, Yeung VTF, Chow CC, Wai HPS, Li JKY, So WJ \& Cockram CS (1997) Simple anthropometric indexes and cardiovascular risk factors in Chinese. International Journal of Obesity 21, 995-1001.

Kruger HS, Venter CS \& Steyn HS (2000) A standardised physical activity questionnaire for a population in transition: the THUSA study. African Journal of Physical Health Education, Recreation and Dance 6, 54-64.

Landsberg L (1986) Diet, obesity and hypertension: an hypothesis involving insulin, the sympathetic nervous system, and adaptive thermogenesis. Quarterly Journal of Medicine 236, 1081-1090.

Langenhoven ML, Kruger ML, Gouws E \& Faber M (1991) MRC Food Composition Tables. Parow, South Africa: Medical Research Council.

Lapidus L, Bengtsson C \& Larsson B (1984) Distribution of adipose tissue and risk of cardiovascular disease and death: A 12-year follow-up of participants in the population study of women in Gothenburg, Sweden. British Medical Journal 289, 1257-1261.

Larsson B, Bengtsson C, Bjorntorp P, Lapidus L, Sjostrom L, Svarsudd K, Tibblin G, Wedel H \& Wilhelmsen L (1992) Is abdominal body fat distribution a major explanation for the sex 
difference in the incidence of myocardial infarction? American Journal of Epidemiology 135, 266-273.

Lean MEJ, Han TS \& Morrison CE (1995) Waist circumference as a measure for indicating need for weight management. British Medical Journal 311, 158-161.

Marckmann P (1995) Diet, blood coagulation and fibrinolysis. Danish Medical Bulletin 42, 410-425.

Marin P \& Bjorntorp P (1993) Endocrine-metabolic pattern and adipose tissue distribution. Hormone Research 39, 81-85.

Modan M, Halkin H \& Almog S (1985) Hyperinsulinemia. A link between hypertension, obesity and glucose tolerance. Journal of Clinical Investigation 75, 809-817.

Mollentze WF, Moore AJ, Steyn AF, Joubert G, Steyn K, Oosthuizen GM \& Weich DJV (1995) Coronary heart disease risk factors in a rural and urban Orange Free State black population. South African Medical Journal 85, 90-96.

Norton K \& Olds T (1996) Anthropometrica. A Textbook of Body Measurement for Sports and Health Courses. Sydney: University of New South Wales Press.

Pouliot MC, Despres JP, Lemieux S, Moorjani S, Bouchard C, Tremblay A, Nadeau A \& Lupien PJ (1994) Waist circumference and abdominal sagittal diameter: best simple anthropometric indexes of abdominal visceral adipose tissue accumulation and related cardiovascular risk in men and women. American Journal of Cardiology 73, 460-468.

Rexrode KM, Carey VJ, Hennekens CH, Walters EE, Colditz GA, Stampfer MJ, Willett WC \& Manson JE (1998) Abdominal adiposity and coronary heart disease in women. Journal of the American Medical Association 280, 1843-1848.

Rossouw JE, Steyn K, Berger GMB, Kock J, Seftel HC \& Gevers W (1988) Action limits for serum total cholesterol: a statement for the medical profession by an ad hoc committee of the Heart Foundation of Southern Africa. South African Medical Journal 73, 693-700.

Seedat YK, Seedat MA \& Hackland DBT (1982) Prevalence of hypertension in the urban and rural Zulu. Journal of Epidemiology and Community Health 36, 256-261.
Seidell JC \& Bouchard C (1997) Visceral fat in relation to health: is it a major culprit or simply an innocent bystander? International Journal of Obesity 21, 626-631.

SPSS (1995) SPSS Windows version 7.0. Chicago, IL: SPSS.

Steyn K, Jooste PL, Bourne LT, Fourie J, Badenhorst CJ, Bourne DE, Langenhoven ML, Lombard CJ, Truter H, Katzenellenbogen J, Marais M \& Oelofse A (1991) Risk factors for coronary heart disease in the black population of the Cape Peninsula. The BRISK study. South African Medical Journal 79, 480-485.

Van Itallie TB (1985) Health implications of obesity in the United States. Annals of Internal Medicine 103, 983-988.

Venter CS, MacIntyre UE \& Vorster HH (2000) The development and testing of a food portion photograph book for use in an African population. Journal of Human Nutrition and Dietetics 13, 205-218.

Vorster HH, Wissing MP, Venter CS, Kruger HS, Kruger A, Malan NT, De Ridder JH, Veldman FJ, Steyn HS, Margetts BM \& MacIntyre UE (2000) The impact of urbanisation on physical and mental health of South Africans in the North West Province of South Africa: the THUSA study. South African Journal of Science 96, 505-514.

Walker ARP \& Segal I (1980) The puzzle of obesity in the African black female. Lancet i, 263.

Walker ARP, Walker BF, Manetsi B, Molefe O, Walker AJ \& Vorster HH (1991) Obesity in indigent elderly rural African women: effects on hypertension, hyperlipidaemia and hypoglycaemia. International Journal of Vitamin Nutrition Research 61 , 244-250.

Walker ARP, Walker BF, Walker AJ \& Vorster HH (1989) Low frequency of adverse sequelae of obesity in South African rural black women. International Journal of Vitamin Nutrition Research 59, 224-228.

World Health Organization (1978) Expert Committee. Arterial Hypertension. Technical Report Series no. 628. Geneva: World Health Organization. 